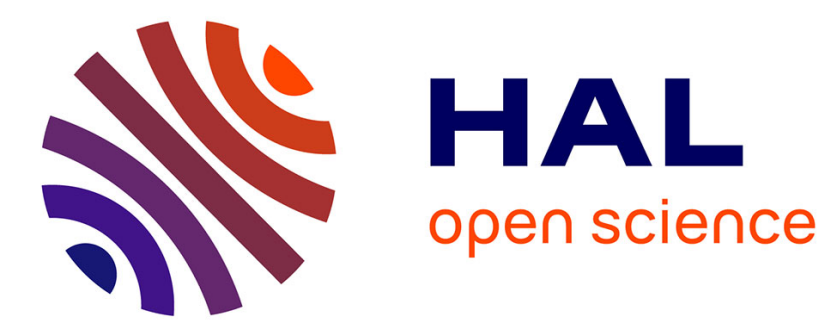

\title{
Rate effect for impact damage initiation in CFRP laminates
}

\author{
W. Stronge, S. Matemilola
}

\section{To cite this version:}

W. Stronge, S. Matemilola. Rate effect for impact damage initiation in CFRP laminates. Journal de Physique IV Proceedings, 1994, 04 (C8), pp.C8-225-C8-230. 10.1051/jp4:1994833 . jpa-00253388

\section{HAL Id: jpa-00253388 https://hal.science/jpa-00253388}

Submitted on 1 Jan 1994

HAL is a multi-disciplinary open access archive for the deposit and dissemination of scientific research documents, whether they are published or not. The documents may come from teaching and research institutions in France or abroad, or from public or private research centers.
L'archive ouverte pluridisciplinaire HAL, est destinée au dépôt et à la diffusion de documents scientifiques de niveau recherche, publiés ou non, émanant des établissements d'enseignement et de recherche français ou étrangers, des laboratoires publics ou privés. 


\title{
Rate effect for impact damage initiation in CFRP laminates
}

\author{
W.J. Stronge and S.A. Matemilola \\ Cambridge University, Engineering Department, Cambridge CB2 IPZ, U.K.
}

\begin{abstract}
Resumé: L'impact d'une petite masse sur une plaque en fibre de carbon laminé, à des vitesses moyennes (jusqu'à $100 \mathrm{~ms}^{-1}$ ) induit trois types de fractures: des longues fentes, des ruptures de fibre et des décollages laminaires. Une analyse élastique a permis de définir, durant l'impact, les contraintes sur la plaque qui ont été ensuite comparées aux observations expérimentales. Les fractures dues aux longues fentes autour du point đ'impact sont causées par des contraintes radiales (perpendiculaires au sens des fibres); elles apparaissent sous le point d'impact près de la surface opposé de la plaque et résultent de tensions et de cisaillement normal aux fibres. Les ruptures de fibre et les décollages laminaires apparaissent sous le point d'impact. Les critères d'initiation des fractures, du type longues fentes, ont été determinés pour les fractures vers l'impact ā hautes vitesse.
\end{abstract}

\begin{abstract}
In carbon fibre composite laminated plates, impact of a small mass at subordnance velocities resulted in three types of initial fractures: yarn splitting, fibre breakage and delamination. An elastic analysis for stresses developed due to impact against the composite plate has been correlated with observations of fracture initiation in impact experiments. Fractures due to yarn splitting developed near the periphery of the contact area due to a tensile radial stress perpendicular to the fibres; this type of fracture also occurred near the distal surface as a result of combined transverse tension and shear on fibres. Under the striker there was fibre breakage and delamination as well. Criteria were obtained for initiation of yarn splitting in composite plates deformed at high rates.
\end{abstract}

\section{INTRODUCTION}

Impact of a foreign object against a composite laminate results in local contact stresses in the region of contact as well as flexural bending of the specimen. Damage to the laminated plate initially appears as microcracks which are not easily detected by commonly employed non-destructive methods, such as ultrasonic scanning or X-ray. The microcracks are barely visible, but they provide an initiation site for cracks that can grow under in-service loads, and they are the precursor of more extensive damage that occurs at a slightly larger impact energy.

Previous studies (Cantwell and Morton, 1989; Gresczuk, 1982) have revealed that the initial damage in a composite plate subjected to impact initiates either near the distal surface in long flexible laminates as a result of large flexural stress, or on the impact surface at the periphery of the contact area in plates that are short and thick. Also, a number of research studies have shown that the fracture stress of composite materials increase at high rates of strain (for example Harding et al., 1988; Kander and Siegmann, 1992). None of the previous studies however, has correlated the 
transient stress state developed in the composite due to impact with the mode and spatial location of fracture initiation.

The present study addresses initiation of fracture in composite laminates subjected to impact by a small missile. Quasi-static indentation and impact tests are conducted with various sizes of missile to capture the initial fracture in resin transfer moulded (RTM) woven fibre composite laminates. The fracture mode and spatial location of initial microcracks are related to the microstructure, as well as to stresses developed in the region of fracture. The state of stress in different regions of the laminate is analysed and compared with both the location and mode of fracture observed from experimental studies. Rate dependent failure criteria are obtained for initiation of fracture in the composite laminates.

\section{MATERIALS AND TEST PROCEDURE}

Composite plates were prepared from Fothergil A0039 carbon fibre fabrics, laid in TACTIX 123/H41 epoxy resin by injection moulding. Each plate contained 24 fabric layers with orientation $\left(45^{\circ}, 0^{\circ}\right.$, $\left.-45^{\circ}, 90^{\circ}, 45^{\circ}, 0^{\circ}\right)_{2 s}$, relative to the longer sides of the plate. This stacking sequence gave a quasiisotropic laminate lay-up. After curing the plates had a nominal thickness of $5.1 \mathrm{~mm}$ and a fibre volume fraction of 0.52 . Mechanical properties of the composite plate are given in Table 1 .

Quasi-static indentation tests were conducted on $35 \mathrm{~mm}$ square size specimens in order to study the different modes of fracture initiation in the composite plates. The static tests used a hardened steel indenter with a $7.94 \mathrm{~mm}$ diameter hemispherical nose. Load was applied at the centre of the specimen in an Instron testing machine at a cross-head speed of $0.1 \mathrm{~mm} \mathrm{~min}^{-1}\left(1.67 \times 10^{-6} \mathrm{~ms}^{-1}\right)$, with the specimen supported continuously on a rigid steel base. An indentation force ranging between $3 \mathrm{KN}$ and $5 \mathrm{KN}$ was applied on successive specimens until damage was first noticed on the cross-section when viewed under an optical microscope.

Table 1: Material properties for Fothergil A0039 carbon fibre fabrics in TACTIX 123/H41 epoxy resin resin transfer moulded composite laminates.

\begin{tabular}{|ll|}
\hline In-plane Young's modulus, $E_{x}, E_{y}$ & $53.48 \mathrm{GPa}$ \\
\hline Through-thickness Young's modulus, $E_{z}$ & $11.51 \mathrm{GPa}$ \\
\hline In-plane shear modulus, $G_{x y}$ & $19.54 \mathrm{GPa}$ \\
\hline Through-thickness shear modulus, $G_{x z}, G_{y z}$ & $3.34 \mathrm{GPa}$ \\
\hline In-plane Poisson's ratio, $\nu_{x y}$ & 0.325 \\
\hline Through-thickness Poisson's ratio, $\nu_{x z}, \nu_{y z}$ & 0.07 \\
\hline Tensile fracture stress for yarn splitting, $Y_{22}$ & $500 \mathrm{MPa}$ \\
\hline Interlaminar shear fracture stress, Sil & $60 \mathrm{MPa}$ \\
\hline
\end{tabular}

Impact tests were conducted on laminated composite plates in order to compare damage initiation patterns for different loading rates. In impact tests a missile fired from a gas gun strikes the centre of a composite plate which measures $25 \mathrm{~mm}$ wide by $65 \mathrm{~mm}$ long. Steel spheres with diameters of $10 \mathrm{~mm}, 7.94 \mathrm{~mm}$ and $4.76 \mathrm{~mm}$, as well as aluminium spheres with diameters of $7.94 \mathrm{~mm}$ and $5 \mathrm{~mm}$ were used as missiles. In one series of tests the specimen was clamped against a rigid steel block during impact, to prevent flexural bending. Another series of impact tests were conducted on plates clamped at the short edges (without back support), using steel missiles with various nose radii. In these tests the impact speed ranged between $26 \mathrm{~ms}^{-1}$ and $82 \mathrm{~ms}^{-1}$, while the kinetic energy of impact ranged between $0.53 \mathrm{~J}$ and $4.61 \mathrm{~J}$.

\section{STRESSES FROM IMPACT ON ORTHOTROPIC PLATE}

Quasi-static indentation and impact on composite plates revealed that there were three different mechanisms of fracture initiation. These were yarn splitting, fibre breakage, and delamination. In specimens where damage first developed on the impact side due to large contact stresses, all three types of fractures were observed. On the other hand, only yarn splitting was recorded near the distal side of specimens which failed due to a large bending stress on the distal side. Typical fractures on both the impact side and the distal side of a carbon fibre composite plates are shown in Fig. 1. In 
the remainder of this section, the initial fractures observed from impact experiments are correlated with the transient state of stress in the laminated composite plate during impact.

\subsection{Stresses Under Region of Contact}

Fig. 1 shows the locations where fractures first developed on the impact side of the carbon fibre composite specimens due to contact loading, as well as the state of stress at these locations. The stress components were calculated using a combination of Hertz contact theory and a vibration analysis which considered flexibility of the plate (Matemilola, 1993). Consider three points in the contact region under a colliding body; these points labelled YS, FB and DL, are located at $(r, z)=$ $(a, 0),(0.9 a, 0.2 a)$ and $(1.2 a, 0.2 a)$, respectively. Here, $r$ is the radial distance from the centre of impact and $z$ is the depth below the contact surface, while $a$ is the radius of the contact area. A radial tensile stress $\sigma_{r}=0.32 q_{0}$ and a tangential compressive stress $\sigma_{\theta} \approx \sigma_{r}$, act on YS as shown in Fig. 1 (where $q_{0}$ is the maximum pressure between the colliding missile and the plate). Under quasi-static indentation fracture initiates at $q_{\mathrm{O}} \approx 1.8 \mathrm{GPa}$ for the composite material considered in the present study.
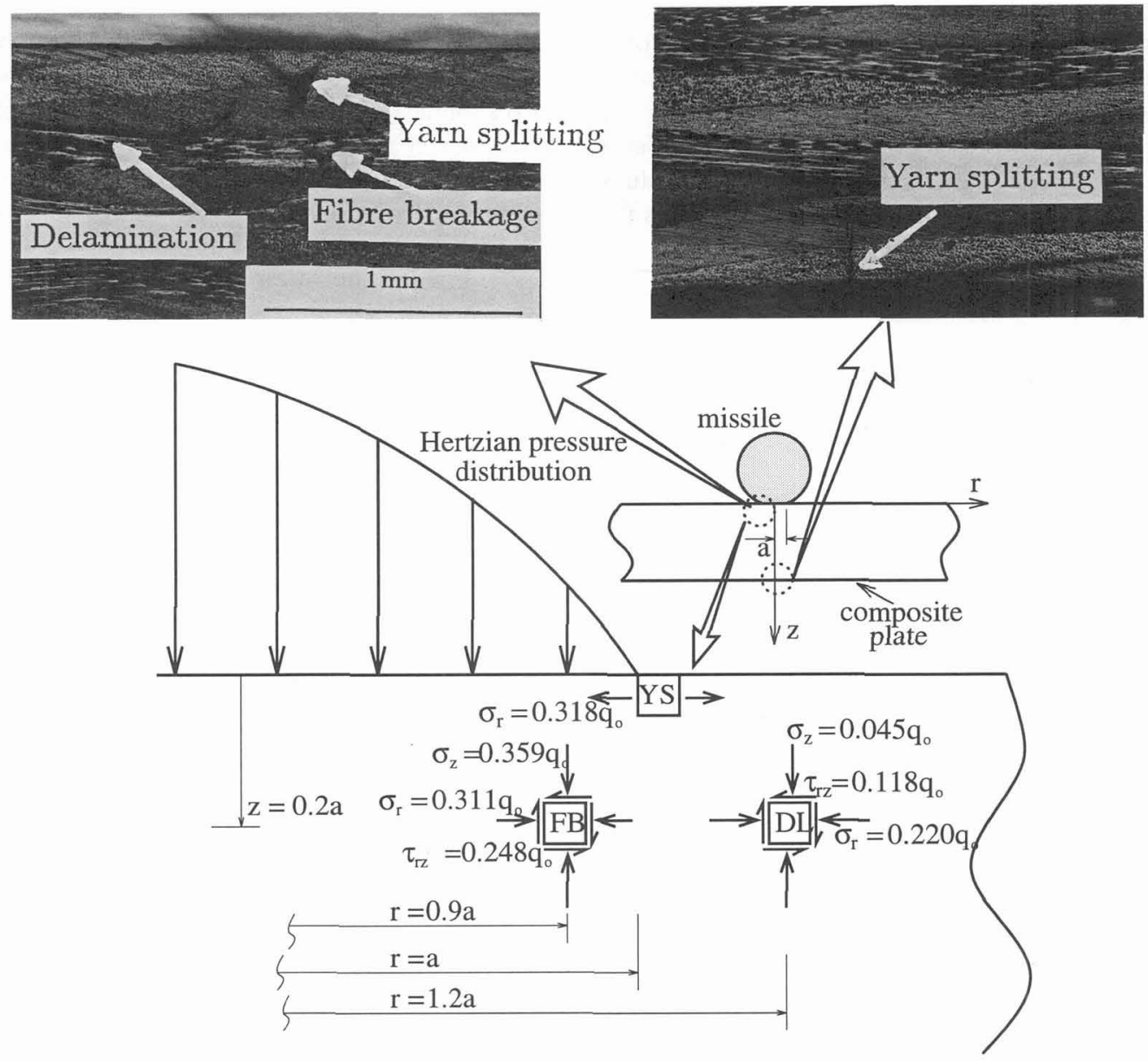

Figure 1: Stresses in contact region where fractures initiated in carbon fibre composites under quasi-static indentation. The maximum pressure at the centre $q_{0}$ is approximately $1.8 \mathrm{GPa}$. 
Yarn splitting tangent to the contact patch initiates at a point along the periphery of contact area where tensile stress normal to the fibres is maximum; this fracture initiates when the stress state satisfies the criterion for fracture presented in Section 4. Due to the orientation of fibres in a composite laminate the normal stress transverse to the fibres varies with position around the periphery of the contact area. Thus, unlike brittle homogeneous materials where ring cracks may develop, fractures do not form along the entire periphery of the contact region.

At the point FB the state of stress is $\sigma_{r}=0.31 q_{\mathrm{O}}, \sigma_{\theta}=0.20 q_{\mathrm{o}}, \sigma_{z}=0.36 q_{\mathrm{o}}$, and $\tau_{r z}=0.25 q_{\mathrm{o}}$, and all the normal stress components are compressive. The shear stress, if acting alone, is large enough to cause delamination at an interface near the region. However, the presence of a large compressive transverse normal stress prevents any delamination from developing. Rather, fibre breakage occurs due to transverse shear on fibres. The transverse shear stress at the point DL is also large $\left(\tau_{r z} \approx\right.$ $\left.0.12 q_{0}\right)$, but the compressive transverse normal stress $\sigma_{z}\left(<0.05 q_{0}\right)$ is comparatively smaller than that acting on FB. Thus, delamination may develop at an interface near this region.

\subsection{Fracture Stress for Different Loading Rates}

Fig. 2 shows the plot of largest transient tensile radial stress at the periphery of contact region when yarn splitting occurred on the impact side of composite plates struck by various missiles at different incident speeds. The figure shows that for initial fracture on the impact side, the fracture stress increased with an increase in the loading rate. This corresponds to an increase in failure strength at high strain rates as reported from previous studies (Harding et al., 1988; Kander and Siegmann, 1992). Despite the different fracture stress values at different loading rates however, there was no detectable difference in the pattern of fractures for composite plates impacted at high or low speeds.

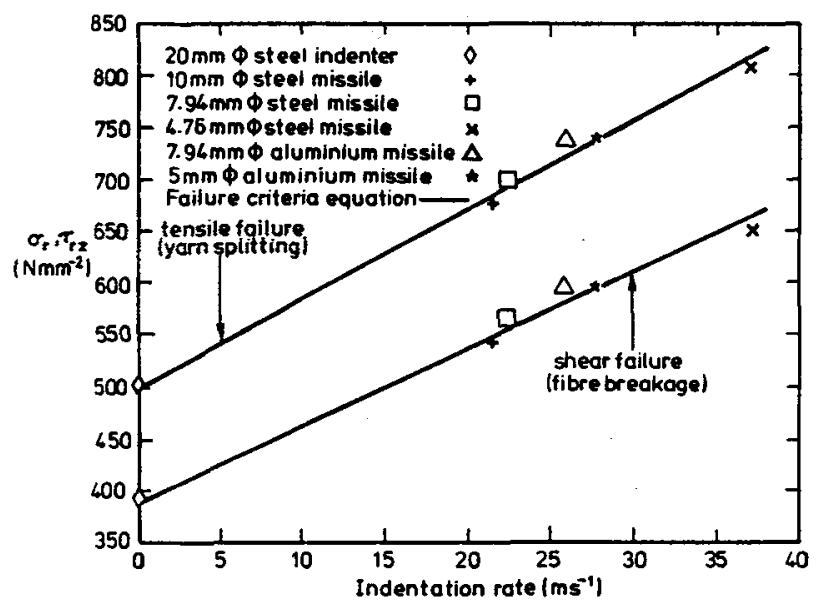

Figure 2: Effect of loading rate on normal or shear stress at fracture initiation in contact region. Measurements from impact tests where steel or aluminium missile struck RTM composite plates.
On the other hand, for specimens which sustained initial fracture near the distal surface, the transient maximum bending stress was relatively unchanged for different thickness plates struck at different rates. One reason for this behaviour is that the strain rates for flexure under impact loading are similar for similar plate sizes, and are much smaller than those in the region of contact. However, this fracture was influenced by the ratio of missile nose radius to plate thickness, $\frac{r}{h}$. Yarn splitting developed first on the distal side of the plate for $\frac{r}{h}>1$, while fracture developed first on the impact side for $\frac{r}{h}<1$ (Matẹmilọla 1993).

\section{FRACTURE INITIATION CRITERIA}

The results from previous studies (for example, Harding et al., 1988; Kander and Siegmann, 1992) suggest that fracture stress increases with loading rate. However, existing failure criteria for composite laminates neglect this rate effect. Here, we propose a failure criterion which accounts for rate effect, based on Hashin's (1980) model. By introducing into the Hashin criterion for tensile failure an 
empirical rate factor $\kappa$ - the slope of the plot of fracture stress against indentation rate - a general failure criterion for yarn splitting of a composite laminate can be expressed as

$$
\frac{\left(\sigma_{22}+\sigma_{33}\right)^{2}}{\left(Y_{22}+\kappa_{22} d\right)^{2}}+\frac{\sigma_{23}^{2}-\sigma_{22} \sigma_{33}}{\left(S_{13}+\kappa_{13} d\right)^{2}}+\frac{\sigma_{12}^{2}+\sigma_{13}^{2}}{\left(S_{12}+\kappa_{12} d\right)^{2}}=1
$$

The yarn splitting criterion Eq. (1) depends on fracture stresses in tension $Y$, and in pure shear $S$. The components of normal stress $\sigma_{i, j}(i, j=2,3)$ are transverse to the fibre axis, and $d$ is the contact deformation rate; i.e. maximum depth of indentation per half contact period. Subscript 1 refers to the direction parallel to the fibre while subscript 3 refers to the direction normal to the plane of the laminate. Eq. (1) is applicable to both the distal and impact surface fractures, as discussed in the remainder of this section.

\subsection{Fracture at Distal Surface}

The largest bending stress in a plate struck by a missile is not significantly influenced by loading rate so on the distal surface the rate term $\kappa$ is zero as in quasi-static loading. Also, on the distal surface the through-thickness stress terms vanish, $\sigma_{33}=\sigma_{23}=\sigma_{13}=0$. Eq. (1) therefore, reduces to

$$
\frac{\sigma_{22}^{2}}{Y_{22}^{2}}+\frac{\sigma_{12}^{2}}{S_{12}^{2}}=1
$$

Eq. (2) suggests that both the in-plane tensile and shear stress components influence the yarn splitting on both the impact and distal sides. In the present study the average value of the fracture stress $Y_{22}$ was obtained from static indentation tests on the composite laminates; $Y_{22}=500 \mathrm{MPa}$. For a laminate subjected to bending in which the fracture surface was orientated at $45^{\circ}$ to the longer sides of the plate, $S_{12}$ was evaluated from (2) as $289 \mathrm{MPa}$. The above fracture stress values $Y_{22}$, $S_{12}$ represent upper bounds on the tensile stress and shear stress values on yarn splitting fracture surface due to bending. For yarn splitting Fig. 3 shows the fracture surface for the interactive effect between the in-plane shear stress $\tau_{12}$ and the normal stress $\sigma_{22}$. Good agreement is obtained between the predicted fracture surface and data obtained from quasi-static tests.

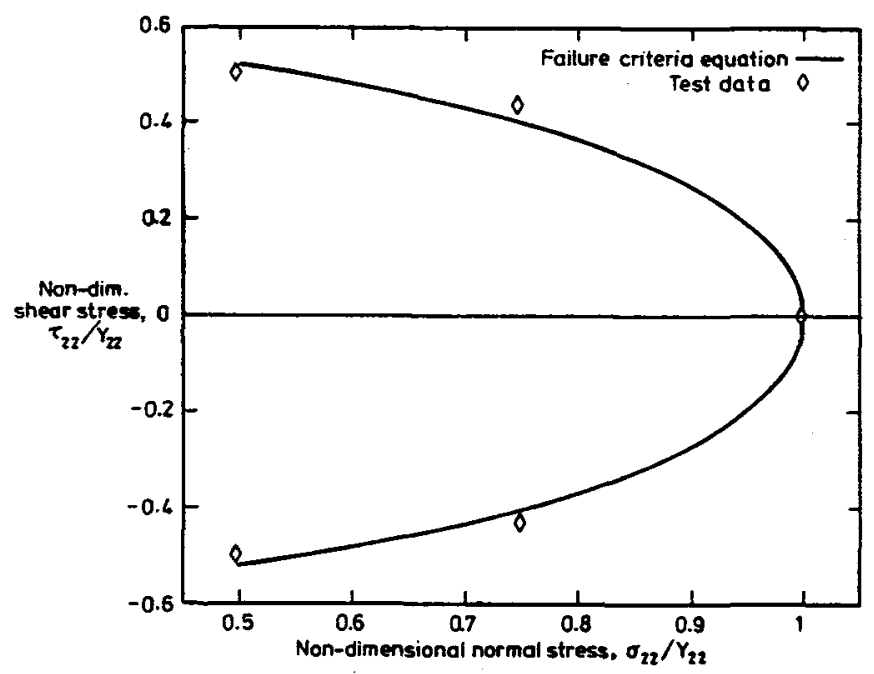

Figure 3: Interactive effect between normal and shear stress components for yarn splitting. For yarn splitting the pure normal stress perpendicular to the fibre direction is $Y_{22}$.

\subsection{Fracture near Impact Surface}

Yarn splitting develops on the impact surface of a composite plate just outside the periphery of contact where some stress components vanish $\sigma_{33}=\sigma_{23}=\sigma_{13}=\sigma_{12}=0$. Here, with inclusion of rate effects, the failure criterion (1) reduces to

$$
\frac{\sigma_{22}}{Y_{22}+\kappa_{22} d}=1
$$


For these composite laminates, the rate factor $\kappa_{22}$ for yarn splitting was $8.5 \mathrm{~N} \mathrm{~s} \mathrm{~mm}^{-3}$. The predicted fracture stress value based on (3) shows good correlation with stresses where fracture was first observed on the impact surface of the laminated composite plate, as shown in Fig. 2.

For fibre breakage and delamination on the impact side, there are strong reasons to believe that the transverse compressive stress component $\sigma_{z}$, has a significant influence on the transverse shear stress $\tau_{r z}$ at which fracture is initiated. These reasons include:

(i) The absence of delamination in the region where fibre breakage occurred, despite the fact that the shear stress $\tau_{r z}$ is roughly six times larger than the interlaminar shear stress $\tau_{i l}$ required for delamination in the absence of transverse compression.

(ii) The transverse shear stress $\tau_{r z} \approx 4 \tau_{i l}$ at the location where delamination was recorded.

For matrix cracking there is an interaction between transverse normal stress and shear stress (e.g. Greenwood, 1977; Swanson et al., 1987). However, the interaction between transverse normal stress and shear stress does not seem to have been investigated for fibre breakage or delamination. Such a relationship will require a test involving a combined normal pressure and shear loading of a composite laminate. For the present, it is difficult to obtain a reliable criterion for these modes of fracture under impact loading.

\section{CONCLUSIONS}

Static indentation and impact tests were conducted on woven fabric carbon fibre laminated composite plates to study the effect of loading rate on initiation of damage. The locations where fractures first developed were correlated with transient stresses developed in the composite plates. The study revealed that fractures due to impact loading initiated by yarn splitting, fibre breakage or delamination, all of which occur independently. All three modes of fracture were observed on the impact side of specimens which failed due to large contact stresses, whereas yarn splitting was the only fracture mode recorded on the distal side of specimens that failed due to large bending stress.

A large transient radial stress at the periphery of the contact patch was the cause of yarn splitting on the impact side, while a large transient transverse shear stress was responsible for both fibre breakage and delamination under the contact region. On the other hand, yarn splitting developed on the distal side due to a combination of in-plane tensile and shear stress components caused by large transient bending. The contact stress value for yarn splitting near the impact surface increased with an increase in the loading rate due to an increase in the fracture stress at high rates of strain. Yarn splitting on the distal side however, was relatively insensitive to the rate of loading since the strain rates for flexure are much smaller than those in the contact region.

\section{References}

[1] Cantwell, W.J. and Morton, J., 1989, "Comparison of the Low and High Impact Response of CFRP," Composites, 20(6), pp. 545-551.

[2] Gresczuk, L. B., (1982) "Damage in Composite Materials due to Low Velocity Impact," in Zukas, J. A. et al. eds., Impact Dynamics, John Wiley \& Sons, New York, pp. 55-94.

[3] Harding, J., Saka, K. and Taylor, M. E. C., 1988, "The Effect of Strain Rate on the Tensile Failure of Woven-Reinforced Carbon/Glass Hybrids," Proc. IMPACT 87, Impact Loading and Dynamic Behaviour of Materials, edited by C. Y. Chiem and others, 1, pp. 515-522.

[4] Kander, R. G. and Siegmann, A., 1992, "The Effect of Strain Rate on Damage Mechanisms in a Glass/Polypropylene Composite," Journal of Composite Materials, 26(10), pp. 1455-3473.

[5] Matemilola, S. A., 1993, Ph D Dissertation University of Cambridge, UK.

[6] Greenwood, J. H., 1977, "German Work on GRP Design", Composites, July, 1977, pp. 175-384.

[7] Swanson, S. R., Messick M. J. and Tian, Z. 1987, "Failure of Carbon/Epoxy Lamina Under Combined Stress," Journal of Composite Materials, 21, pp. 619-630. 